\title{
Implementation and evaluation of an a psychosocial educational programme to facilitate the reintegration of incarcerated women who had dumped babies and / or committed infanticide
}

\author{
Sumpi Ndempavali *, Amukugo Hans Justus \\ Lecturers, School of nursing and School of Public health, Faculty of health Sciences University of Namibia \\ *Corresponding author E-mail: nsumpi@unam.na
}

\begin{abstract}
This paper focuses on the process of the implementation and evaluation of a psychosocial training programme to facilitate reintegration of the imprisoned women who have dumped babies and / or committed infanticide. This paper consists of two sections. The first section deals with the implementation of the psychosocial training programme while the second section evaluates the implementation and the outcomes evaluation of the of the programme. The programme was completed during a three-day workshop at the Correctional Facility in Namibia.
\end{abstract}

Keywords: Implementation; Evaluation; Psychosocial; Educational Programme; Facilitate; Reintegration; Incarcerated; Women; Dumped Babies Committed; Infanticide.

\section{Introduction}

It is difficult to estimate the true extent of infanticide and baby dumping in Namibia, since such cases may go unreported. However, police statistics and anecdotal information suggest that the problem is significant (LAC, $2007 \&$ 2008). Newspapers report that in most cases babies are abandoned, flushed down toilets, or dumped in pit latrines. Many are discovered on rubbish dumps, sewage works, and sewage outlets at isolated places. There are a few other indicators of the extent of the problem. For example, in April 2008 staff at Gammams Water Care Works in Windhoek estimated that they had discovered an average of 13 bodies of new-born babies each month amongst the human waste flushed down toilets. The situation of baby dumping and infanticide is not unique to Namibia as seen in the background information of this study.

Baby dumping is considered as a serious criminal offence in $\mathrm{Na}$ mibia (LAC, 2008). There are women incarcerated in Namibia for having committed either baby dumping or infanticide. Due to the nature of the crime these women committed and the thoughts of feeling rejected by their family, they fear of reintegration after being released from custody into their respective society. It is clear that these women cannot be in prison forever, therefore, there is a need to develop a means of facilitating the reintegration. Bentu (2013) states that perpetrators of baby dumping and /or infanticide are likely to have reported physical, sexual, and emotional abuse in their families of origin (especially in blended families), and subsequently in their later intimate relationships. $\mathrm{He}$ further points to the evidence which suggests that often the father would have denied the pregnancy and the parent(s) would have reacted with extreme anger, driving the young woman into isolation during pregnancy. Women who dump babies and / or commit infanticide could experience a similar situation. However, no study has been done to look at the experiences of these women All these aspects can give rise to negative psychological and emotional issues to these women, especially the fear they are experiencing about being released from custody.

In an attempt to determine the underlying causes of baby dumping, the Ministry of Gender Equality and Child Welfare in collaboration with the Ministry of Youth, National Service, Sport, and Culture and with the financial and technical support of UNICEF conducted a multiple choice text message survey in 2011 to gauge the public attitudes towards baby dumping. That survey revealed that baby dumping and infanticide were the most likely response to an unwanted pregnancy and the top three reasons were fathers who denied paternity, mothers who were still students, and mothers who were unaware of alternatives; such as foster care and adoption (Ministry of Gender Equality and Child Welfare, 2009). The perpetrators of this gruesome act are facing pressure and rejection from the community. Instead of rejecting or stigmatising them, the community should understand the anxiety they go through and provide them with love and compassion, information, and moral support. Social support can assist the young mother to be more rational while increasing the likelihood that she will not abandon the innocent baby (Ciccarelli, 2009). Therefore, De Bruyn \& Parker (2005) state that the consequences of baby dumping and infanticide are imprisonment and these consequences lead to many psychological and psychosocial problems for the ones who commit such atrocities. Young women and girls are likely to deny that they are pregnant due to fear and shame. It is this denial that causes them to risk their lives in an attempt to end the unplanned pregnancy by instituting abortion or committing infanticide and / or baby dumping. Ideally, any young woman who faces an unwanted pregnancy should be able to count on her parents or guardians for support. It will be easier for an adolescent to confide in the adults who care for her when they have an open, loving, and non-judgmental relationship and when she does not fear negative repercussions; such as scorn, punishment, abandonment, or coercion when seeking a solution to her problem. 
Currently, there is no study in Namibia that has interrogated the development of a psychosocial training programme that facilitates the reintegration of women who have dumped babies and / or committed infanticide. Therefore, the general goal of this study is to gain insight into the experiences of women who have been incarcerated as a result of dumping babies and / or committing infanticide. The goal of the study is to develop programmes and services that will enable the women who have dumped babies and / or committed infanticide to be successfully reintegrated into their families and their respective communities or society. This goal indirectly relates mainly to the Millennium Development Goals as one of the policies that Namibia conform to as an initiative aimed at reducing the infant or child mortality rate in adherence to the Namibian constitution that guarantees every person in Namibia the right to life, even the right to life of the unborn baby.

In order to address the growing problem of baby dumping and improving the lives of the children instead, the Legal Assistance Center (2011) has called for an enactment of the Child Care and Protection Act. The Act has been opened to public debate because Namibia does not know yet how to tackle this problem. Kangandjera and Mapaure (2009) state that in any caring society, the importance of child welfare cannot be overemphasised because the future welfare of the entire community, as well as its growth and development depend on the health and well-being of its children. Children need to be regarded as valuable national assets because the future well-being of the nation depends on how its children grow up and develop.

Greiner (2001-2008) mentions that some parents in Nigeria recklessly abandon their babies in streets while other ones take them to orphanages and beg workers to take them, and some women even give birth at orphanages. Such kids are being taken to social welfare, are registered with the government, and are distributed to orphanages. Various orphanages have been established all over Nigeria to ensure that such babies have a comfortable home.

The Gauteng Province in South Africa, dumping babies are increasingly becoming a large part of non-natural, undetermined deaths in the zero to four-year age group. These babies are dumped in dustbins and gutters, some are aborted or miscarried, and new-borns are disposed. This behaviour represents $60 \%$ of undetermined deaths of young children (Ramaklas, 2010). Some community members have come up with a facility that is called "Baby Moses" in their endeavour to make a difference. From "Baby Moses", the children are placed with families, put into foster care, taken into private homes, and some are adopted (Daily Maverick, 2012).

Modie-Moroka (2011) mentions that there is a familiar but shocking catalogue of stories; for example, lifeless infants being dragged by dogs, foetuses blocking flush toilets, desperate cries of infants in pit-latrines, children lying cold at the roadside, and live babies saved from pit latrines who are covered in human excreta. Police records between 2005 and 2010 in Botswana indicate that at least 450 babies have suffered this fate. Botswana has designed separate offences for those who commit infanticide, since they acknowledge that there may have been exceptional circumstances involved in the crime. The government of Botswana states that it is in essence a challenge for the government to put in place structures for baby dumping that will promote the wellbeing of the child as outlined in the Children's Act of 2009. Modie-Moroka (2011) also mentions that the establishments of safe haven centres are long overdue and DNA banks should be established to help trace the parents of the abandoned babies. This intervention should promote responsibility and readiness for parenthood by both parents while deterring many from committing this kind of offence (Dzimiri, 2013).

Similar cases of baby dumping are found in Malaysia where people who are responsible for dumping babies who subsequently die would be investigated for murder while abandoned babies who are found alive would be classified and investigated as cases of attempted murder (Salam, 2013). In Kuala Lumpur, the capital city of Malaysia, the baby dumping statistics are critical as mentioned in the introduction. A comparative research project in Malaysia
(Mazbah, Abdullah, Jaafar, Tagaranao, \& Safian, 2014) strongly suggests that baby dumping offender ought to be penalised. They state that there is a need to create and increase awareness about unwanted pregnancies while emphasising that studies need to be conducted to assess the level of awareness among the target group and also to examine the provision of alternative or preventive measures, such as baby hatches. The availability of preventive methods does not aim at encouraging a crime; it aims at avoiding more babies being dumped at dangerous places and the increased possibility of death. As a recommendation, they state that it is perhaps necessary to introduce a new law or section in the Penal Code with regard to baby dumping that clarifies the definition of baby dumping and identifies who specifically could be penalised for this crime. At the moment, legislation about baby dumping does not exist in Malaysia. They also emphasise the establishment of orphan care interventions because an increasing number of babies are being abandoned or dumped in unimaginable places; such as waste dumps, bushes, drains, and public toilets.

In Hamburg, Fernandez (2008) mentions that baby hatches opened in 2000 and since then more than 200 have opened across Germany, providing places of safety and care for abandoned babies. He also states that there are $40-60$ babies killed in Germany every year and that their bodies are found in the toilets, forests, attics, and carrier bags.

There is no denying that baby dumping has become a grave social phenomenon that is drawing nationwide attention in China. In general, the infants who are discarded are born either out of wedlock, with some physical deformity, or in violation of governmental family planning regulations. The family planning policy, known as the one-child policy, is a population control policy of the People's Republic of China. As a result, the overwhelming majority of these discarded babies are girls, victims of traditional ideas that value men and disparage women. Chinese authorities have built a "baby abandonment" building where parents can anonymously leave their unwanted children.

This study emphasises that the young women who commit heinous crimes of baby dumping and infanticide are often immature and inexperienced leading to situations that force them to make decisions that are not often the best ones. The general insight includes the realisation that most of these young women commit these crimes at the spur of the moment and the root causes are well-known. These root causes include such factors or reason as tradition because some young women fear rejection by their communities or family if they are found to have had a baby outside of marriage. The economic state of the young mothers and their male partners who are denying paternity also contribute to baby dumping cases, since they are not able to raise a baby on their own.

As a matter of fact, women who have dumped babies and / committing infanticide are subjected to physical, social and psychological wretchedness, and socio-economic destitutions. These women find themselves incarcerated as a consequence of the atrocious acts they have committed while they fear the reintegration with their families and communities as result of rejection.

However, an educational programme can be effective to facilitate the reintegration of the incarcerated women with the purpose of overcoming their feelings of fear and rejection and prepare them to integrated into the society.

\section{Methodology}

The educational programme was developed according to the themes that had been extracted from the interviews and from the field notes. Since the population of women who dumped babies and / or committed infanticide consisted only of eleven women, the researcher with the permission of the supervisor decided to conduct focus group discussions with parents, pastors, male partners, and correctional officers. This was done to give weight to the content of the educational programme that was going to be developed. The implementation was designed to cover topics that assisted women who had dumped babies and / or committed infanti- 
cide during their reintegration period. The implementation was in the format of a workshop, conducted over three days to include the orientation, working, and terminal phases. It was vital to evaluate the guidelines after they had been implemented to enable the researcher to identify the weaknesses of the guidelines with the purpose of affecting the necessary improvements. Written and / or verbal feedback events were conducted after the daily workshops with the participants through evaluation forms. A follow-up was conducted after two months with all the women who had dumped babies and / or committed infanticide and attended the workshop to evaluate the effectiveness of the guidelines. Figure 1 illustrates the four phases of this research study.

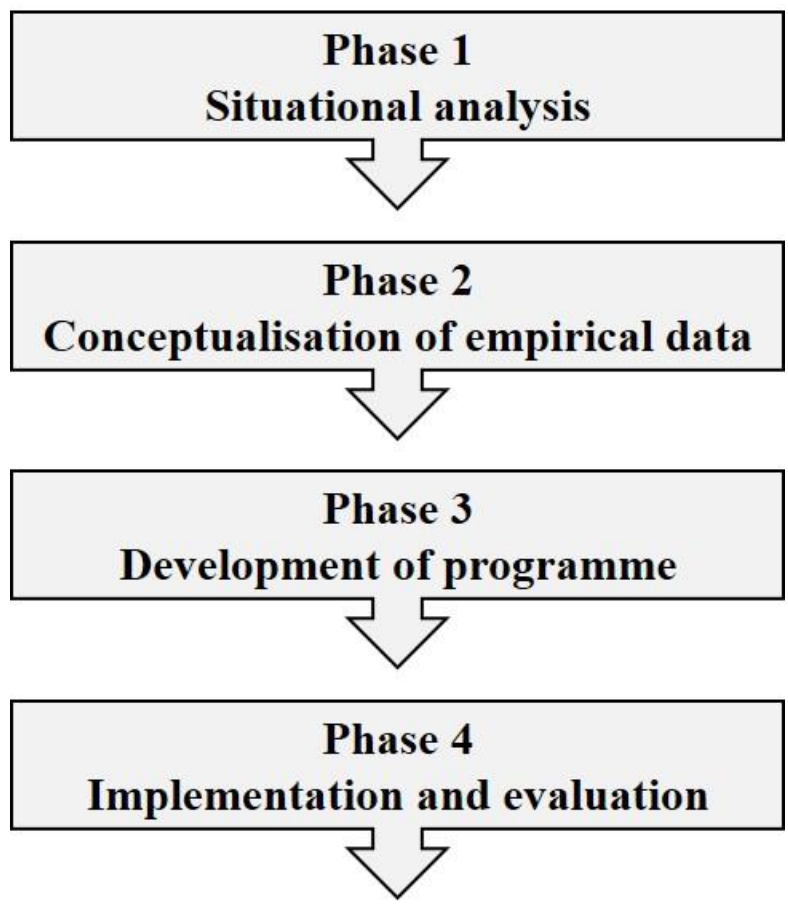

Fig. 1: Illustration of the Four Phases of the Research Study

\section{Results}

The results of this paper is based on the implementation and evaluation of the educational programme to facilitate the reintegration of incarcerated women who had dumped babies and / or committed infanticide. For the implementation the focuses on workshop itself (schedule); learning technique; facilitation technique; learning content, group norms and description of the phases of the educational programme. While for the evaluation focuses on focuses on programme evaluation planning; evaluation of general of the participants' general view and planned programme evaluation to support women who dumped babies and or commit infanticide. This includes finding from the FGDs after the programme implemented.

\section{Implementation}

Careful organisation and preparation was needed to ensure the smooth implementation of the programme. With this principle in mind, the researcher created a safe and favourable environment to facilitate learning and to augment the participants' knowledge and skills. For the aims of the programme to be successfully implemented, it was essential to carry out certain activities in advance. This methodology is supported by Rew (2005) who explains that effective organisation creates a safe environment conducive to the participants' exploration and discovery, as well as one that extends their skills.

The programme implementation also consisted of a work plan that was drawn up to provide guidelines about the content to be implemented; as well as when, by whom, and how it should be im- plemented (Watson, 2011). The implementation of each session was based on specific objective activities and outcomes to assist the women who had dumped babies and / or committed infanticide with the reintegrated process. The participants evaluated each session and that evaluation was done at the end the workshop. The post-evaluation of the feasibility of the training programme was conducted two months after the implementation.

Prior to the programme implementation, the women who had dumped babies and / or committed infanticide were asked whether they were willing to participate in the programme. After all the plans and preparations were thoroughly done, the researcher contacted the participants and the implementation of the programme commenced in the format of a workshop at the Oluno Correctional Facility, Ondangwa. A workshop for 11 women who had dumped babies and / or committed infanticide was conducted over three days. The workshop schedule was timely communicated in writing to the participants which included particular aspects about the programme implementation.

Programme schedule: The programme facilitator was flexible with the schedule of the programme that was divided into three sessions to be covered during a two and half day workshop. The facilitator also adhered to the programme schedule to make sure that all items on the programme received due attention and that all training activities were completed. Nonetheless, it as necessary to make unexpected changes to the programme schedule and to the programme activities. The uniqueness of the participants' learning abilities was taken into consideration. The facilitator also took into consideration the individual needs of the participants and responded to them as they arose, for example language barriers.

Time schedule: The workshop was held from eight o'clock in the morning the first day and it went until four thirty in the afternoon. Icebreakers were used in between the programme activities to help participants experience less stress or tension by making the learning experience enjoyable. The participants registered for the workshop by 08:00 in the morning. The time schedule provided for participants to have tea and lunch during the course of the day.

The venue: The participants met in a well-organised room with sufficient space and without distraction. The correctional service boardroom for staff was the chosen venue for the workshop. The venue was suitable and spacious; an informal sitting arrangement was adopted to put participants at ease and to contribute to the smooth running of the programme implementation. The informal sitting arrangement created an environment conducive to open communication and a feeling of freedom to participate without fear and prejudice. For group work and other activities, tables and chairs were prepared in the configuration of a circle.

\subsection{Learning techniques}

Effective learning is observed when integrated learning methods are used and when learners are mutually supportive. Therefore, the appropriate methods enable participants to benefit from the information and the learning experience. In this study, using different learning techniques were employed to assist the women who had dumped babies and / or committed infanticide in their learning endeavour, as one particular method might have benefitted one learner while the rest of them would not have reaped the benefits of the educational programme.

\subsection{Facilitation techniques}

To facilitate means to guide and to enable participants to uncover and discover their existing knowledge, to explore their potential, and to identify their weaknesses (Neill, 2006). The facilitator's approach to learning makes a classroom a highly participative and richly rewarding environment. Knowing a person's learning style enables learning to be orientated according to the preferred method (Kolb, 1984). Experiential or action learning methods are said to increase the retention rate to $80-95 \%$ (Hazelhurst, 2013). Facilitation is a commonly used approach during workshops. In this study, the facilitation was used to guide the participants through 
the learning content of the training programme and it was found to be a useful method for the researcher in her role of facilitator. This approach starts with an orientation phase, progresses to a working phase, and culminates in a termination phase (Quinn, 2007). The facilitation technique used were roleplay, group discussion and lecture methods (Poorman, 2002; Dawson, 2010; Neill (2006).

\subsection{The learning content}

For implementation, the researcher had developed content for a three-day workshop for women who had dumped babies and / or committed infanticide. The content was structured as follow:

- Session I: Enhancing knowledge and skills to understand and manage the psychological challenges affecting women who had dumped babies and / or committed infanticide.

- Session II: Enhancing knowledge and skills to understand and manage the socioeconomic challenges of women who had dumped babies and / or committed infanticide, as well as enhancing support from family, male partners, and the community.

- $\quad$ Session III: Enhancing knowledge and skills to understand and manage the challenges of the reintegration process experienced by women who had dumped babies and / or committed infanticide and counteracting those challenges through well-planned interventions.
- Session IV: Enhancing knowledge and skills to understand and manage challenges with regard to the legal and ethical framework for women who had dumped babies and / or committed infanticide.

\subsection{Group norms}

Group expectations and group norms had been discussed with the participants at the beginning of the programme before the training sessions commenced to obtain their input with regard to group norms. Those expectations and norms had to be maintained throughout the programme. In order to facilitate communication during the programme, participants wore name tags that displayed their preferred names for the purposes of the workshop. The group members were once again assured that confidentiality would be respected and observed.

\subsection{Description of the phases of the educational pro- gramme}

The programme was implemented in three phases and the researcher was the facilitator of this educational programme as illustrated in Figure 1.

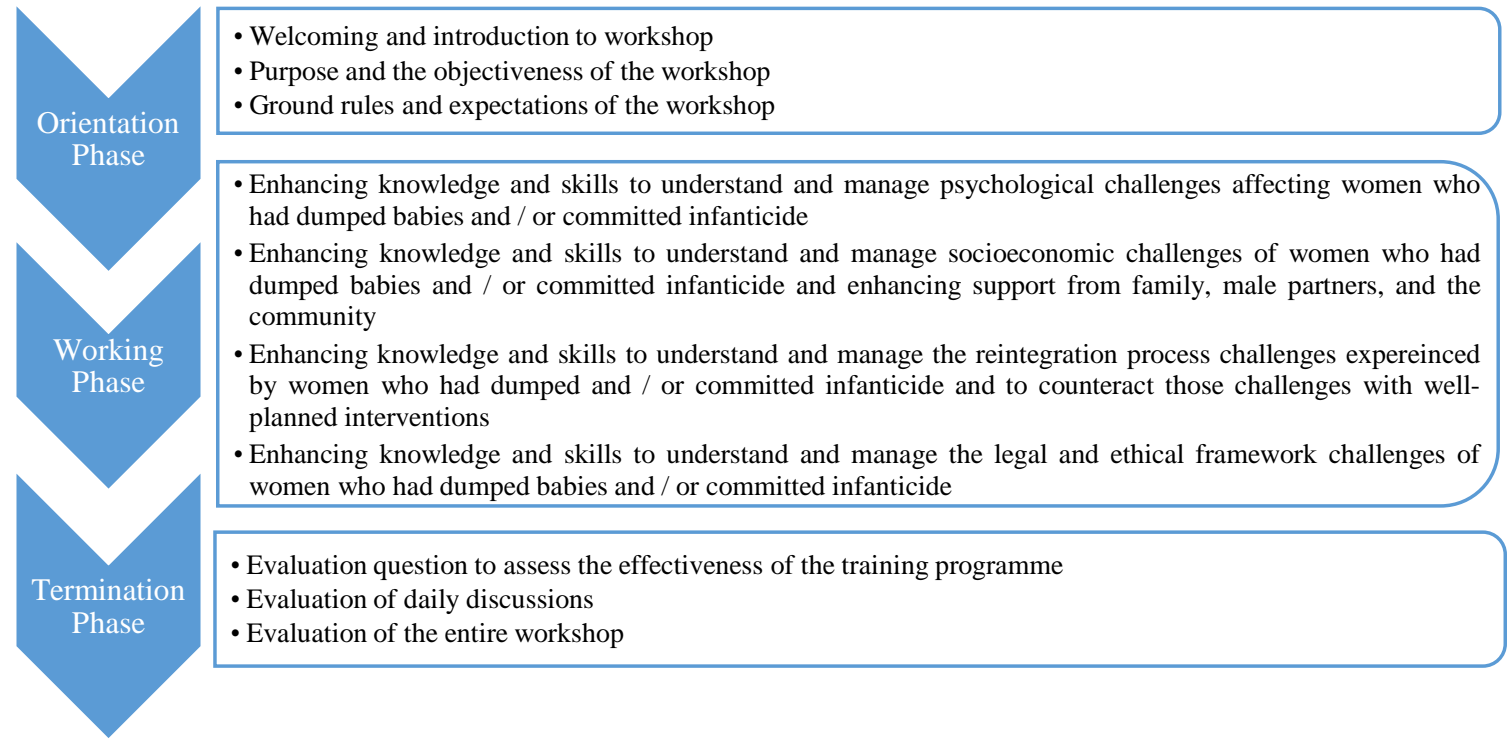

Fig. 2: Illustration of the Implementation Process of A Training Programme.

Orientation phase: During the orientation phase, the researcher met with the participants. They were welcome and introduced to assist with establishing a rapport and trusting relationship between the researcher and the participants. The facilitator as the agent applied her knowledge and skills to develop a relationship between herself as an agent and the women who had dumped babies and / or committed infanticide who were in the as. The group expectations and ground rules were explained and discussed at the commencement of the workshop and everybody respected those rule throughout the workshop. Freedom of expression of views and of opinions about baby dumping and infanticide was encouraged and respected.

Working phase: This phase focused mainly on educating the women who had dumped babies and / or committed infanticide about the psychosocial challenges of reintegration. During this phase, the major goals of the programme were presented followed by the themes identified during the data analysis process of the research study. The facilitator started with an introduction and thereafter introduced the content pertaining to the theme for the specific session. Discussions were held after various sessions were presented during the workshop. Finally, at the end of this session, all information presented during the workshop was summarised and the sessions were evaluated. It was during this phase of evaluation that women who had dumped babies and / or committed infanticide shared their experiences, including the psychosocial challenges they were facing.

It was also during the evaluation phase that group activities were discussed to enhance interpersonal relationships and communication skills that would augment the reintegration process. The participants' thinking and decision making abilities were enhanced while they were discussing common experiences during this phase. The sessions were of such a nature that they addressed the psychosocial needs and the management of the needs of women who had dumped babies and / or committed infanticide, as well as the need to be successfully reintegrated into the society.

The termination phase: This phase involved the closure of the workshop. During this phase, women who had dumped babies and / or committed infanticide were given an evaluation question to 
assess the effectiveness of the training programme with regard to daily workshop activities, discussions, and the workshop in general. Also in this final phase, knowledge and skills with regard to psychosocial needs and management, interpersonal relationships, communication, and the mobilisation of support systems were realised during the internalisation segment of the experiential learning cycle. Finally, the implementation outcomes of the psychosocial training programme for women who had dumped babies and / or committed infanticide sought to successfully reintegrate them into the society after their release from prison.
The participants were assured of confidentiality at all times; therefore, they were encouraged to express themselves liberally and to give their points of view and opinions without restrictions about the issue of baby dumping and infanticide. After the introduction and explanation of the ground rules and their discussion, activities for deliberation for the day were outlined and presented. Figure 6.2 describes the planned activities for the three days.

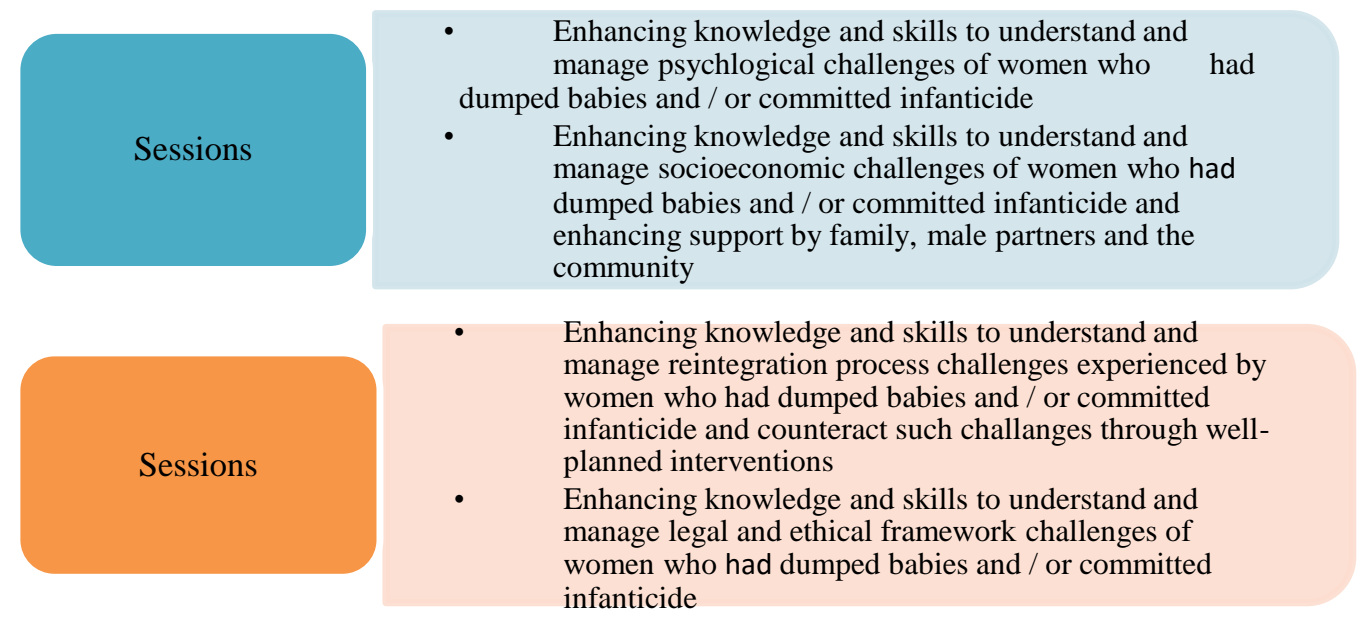

Fig. 3: An Illustration of the Sessions Presented at the Workshop.

The aim of the educational programme approach

The aim of the educational programme was to facilitate the reintegration of incarcerated women who had dumped babies and / or committed infanticide. That was accomplished by conducting educational sessions based on the data collected during Phase 1 (situational analysis) of the study.

Objectives of the educational programme

The educational programme needed to be informed by the programme objectives that were formulated to address the content of the educational programme. The objectives were derived from the challenges to achieve the aim of the educational programme and sought to enhance the knowledge and skills to understand:

Table 1: A Psychosocial Educational Programme to Enhance the Reintegration of Incarcerated Women who had Dumped Babies and / or Committed Infanticide in Namibia

\begin{tabular}{|c|c|}
\hline Aspect & Description \\
\hline $\begin{array}{l}\text { Programme } \\
\text { objectives }\end{array}$ & $\begin{array}{l}\text { To enhance the knowledge and skills of women to under- } \\
\text { stand: } \\
\text { and manage psychological challenges affecting women } \\
\text { who had dumped babies and / or committed infanticide; } \\
\text { and manage socioeconomic challenges of women who } \\
\text { had dumped babies and / or committed infanticide by } \\
\text { enhancing support from family, male partners, and the } \\
\text { community; } \\
\text { and manage the reintegration process challenges experi- } \\
\text { enced by women who had dumped babies and / or com- } \\
\text { mitted infanticide and counteracting those challenges } \\
\text { through well planned interventions; and } \\
\text { legal and ethical frameworks challenges and their impli- } \\
\text { cations for women who had dumped babies and / or } \\
\text { committed infanticide. }\end{array}$ \\
\hline $\begin{array}{l}\text { Programme } \\
\text { structure }\end{array}$ & $\begin{array}{l}\text { The programme was developed to be implemented in the } \\
\text { format of a workshop. }\end{array}$ \\
\hline $\begin{array}{l}\text { Programme } \\
\text { approaches }\end{array}$ & Kolb's learning theory and adult learning approach. \\
\hline $\begin{array}{l}\text { Programme } \\
\text { phases }\end{array}$ & Orientation phase, working phase, and termination phase. \\
\hline
\end{tabular}

Description of the content of the educational programme

The objectives were divided into tables with their corresponding content that the researcher created on the basis of data analysis. All the reflected content in the tables below were the activities the researcher had to carry out in order to facilitate the preparation for reintegration by women who had dumped babies and / or committed infanticide. The content was discussed in the previous article. The content outlined according to the following objectives:

- Objective 1: To enhance the knowledge and skills to understand and manage psychological challenges of women who had dumped babies and / or committed infanticide

- Objective 2: To enhance the knowledge and skills to understand and manage socioeconomic challenges of women who had dumped babies and / or committed infanticide

- Objective 3: To enhance knowledge and skills to understand and manage the reintegration process challenges of women who had dumped babies and / or committed infanticide

- Objective 4: To enhance knowledge and skills to understand and manage the legal and ethical framework challenges of women who had dumped babies and / or committed infanticide.

\section{Evaluation}

The previous session focused on programme implementation. According to Pretorius (2008), programme evaluation is the assessment of whether the programme activities have been congruent to the set programme. The participants of the programme were asked to voluntarily participate in the evaluation of the programme. Programme evaluation was done after each session to determine how effective the programme activities had been and to measure the impact of programme activities. A comprehensive evaluation was done at the closure of the workshop to assess the objectives and activities of the programme. After each session, the participants were given evaluation forms to express their views 
without limitation, as well as to provide their opinions about the programme activities. The evaluation enabled the researcher to make the necessary modifications or additions to the programme, as well as to accommodate participants' recommendations for the programme. Furthermore, a qualitative evaluation was conducted with the participants who described their experiences with regard to the programme activities. Another purpose of the evaluation was to determine whether the researcher had reached her objectives of successfully reintegrating women who had dumped babies and / or committed infanticide in the family and society. An additional purpose of the evaluation was to assess whether the researcher needed to include necessary improvements in the programme (Dawson, 2010).

For the purposes of this study, processes and outcomes evaluation were conducted as proposed by Metz, Bowie and Blasé (2007). A process evaluation was conducted immediately after the implementation session to assess the feasibility of the programme implementation. The outcome of the programme evaluation was conducted three months after the implementation of the programme to determine whether the women who had dumped babies and / or committed infanticide were successfully reintegrated within their family and into society in general.

Programme evaluation planning

Evaluation is defined as a systematic collection of information about activities, characteristics, and outcomes of a programme (Fertman \& Allensworth, 2010). It aims at providing feedback on whether the aim and objectives of the programme were achieved by utilising different approaches to examine the goals, processes, and outcomes of the programme (Jacobsen, 2011). This means that evaluation is conducted in order to determine whether the programme had been implemented as intended; was effective (had reached the goals and objectives); and was efficient.

Evaluation of participants' general views of programme implementation

For the purpose of the evaluation, data was collected by means of filling in the evaluation tool that had been compiled by the facilitator and distributed to the participants to write down their individual responses. Open-ended questions were used in order to allow participants to express themselves without being prompted. Evaluation usually engenders substantial information that may comprise irrelevant and unrealistic data. Conversely, in the context of this study, the researcher anticipated that the data provided would contribute to decisions about the programme, as well as to an improved understanding of what was going into the reintegration of imprisoned women who had dumped babies and / or committed infanticide.

Discussion of the evaluation of the programme implementation by the participants

Upon request, the participants were asked to provide their comments about the workshop presentations and what they had learnt, what they understood most or did not understand, as well as providing their general comments about the presentation and content of the educational programme. The worth of learning and information determined the quality of the programme activities by the participants according to their answers to the evaluation questions. The majority of the participants pronounced the programme as worthwhile and effective because they felt that their interpersonal and communication skills were enhanced and that they were empowered to assert themselves. The evaluation guide for this study was designed and was handed out to the participants for their comments and recommendations every day (6).

Planned programme evaluation to support women who had dumped babies and / or committed infanticide after three months

This type of evaluation was necessary to determine the effectiveness and the impact of the programme, as well as to appreciate the level of understanding of the information formerly given during the workshop. On the other hand, none of the women who had dumped babies and / or committed infanticide were released from prison yet in order to establish whether they found the programme significant. Therefore, the participants were only evaluated on the information they had acquired during the workshop after three months. It was, therefore, also critical that the tools used for data collection were as trustworthy and effective to determine the definite effects of the programme as much as possible. Nevertheless, there was a substantial change noticed in the understanding of aspects in respect of baby dumping and infanticide by the participants in the three months after the programme implementation in comparison with the conclusion immediately after the training had taken place.

Focus group discussions

A focus group discussion is defined as a group of interacting individuals having some common interest or characteristics brought together by a moderator who uses the group and its interaction as a way to gain information about a specific or focused issue (Marczak \& Sewell, 2008). A group of nine participants were guided by a facilitator (researcher) who introduced the topic for discussion and helped the group to participate in a lively and natural discussion amongst themselves. Focus group participants were characterised by homogeneity, that is women who had dumped babies and / or committed infanticide, but with sufficient variation to allow for contrasting opinions.

Five open-ended questions were carefully planned and used during the focus group discussions and they aimed at exposing perceptions and experiences of programme participants, as well as stimulating and capturing in-depth discussions during the interview. These questions were conversational, natural and one-dimensional (they asked only one question at a time). The facilitator used probing during the focus group discussions when asking questions in order to get additional information (Ribeiro, 2008). The facilitator started the discussion with a thought provoking question about the programme implementation after opening the general discussion and before proceeding to the questions. The following questions were developed for the focus group sessions:

- What did you perceive with regard to the general factors that influence baby dumping and infanticide?

- What is your opinion about the self after you have received all that information in respect of self-awareness?

- In what way is your life different with regard to psychosocial challenges as a result of your participation in the programme?

- How do you view your interpersonal relationships and communication skills after your participation in this programme?

- What new and different things have you learnt with regard to mobilising support systems as a direct result of volunteering or participating in this programme?

- If you could change anything about the reintegration process after your participation this programme, what would it be?

- Opening the general discussions of the focus group discussion.

In conducting the focus group interviews, the facilitator started the discussions by first thanking the group for attending, and then went on to explain how the participants were selected. The facilitator also gave the expected length of the interview session, i.e. only one hour. A brief explanation of the process of the discussion that helped to make all participants more relaxed and ready to participate was provided. Each individual introduced herself by first name only. This was to provide credibility to the research study and to make each participant more comfortable with the other participants in the group. The facilitator explained that a voice recorder was going to be used for clarification purposes only and that no connection was going to be made between the comments shared and the individual participants in order to secure confidentiality. Ground rules were established, shared, and given consensus support. The ground rules included:

Everyone will have the opportunity to speak one at a time; No answer is right or wrong, rather they are just differing views; No one is obliged to answer a certain question; and Please speak one at a time so that comments will not be garbled or misinterpreted.

The physical environment of the focus group discussions 
It was important for the facilitator to choose or set up a physical space for the focus group interviews that was going to make the participants feel welcomed and comfortable. The environment was neutral, private, free from distractions, and easily accessible. The facilitator or interviewer created a permissive and nurturing environment that encouraged different perceptions and points of view and kept the discussions flowing and focused. The participants were arranged in a circle, and were told where the bathrooms were. It was important to consider potential distractions, such as background noise that might disturb the proceedings of the focus group discussions.

Furthermore, Burns and Grove (2009) state that the use of focus groups may assist the participants to express and clarify their views in a way that is less likely during a one-on-one interview. Focus group discussions were chosen as a feasible tool for data collection because it was going to assist with deepening the understanding of baby dumping and infanticide, as well as gathering the information about the range of knowledge, opinions, experiences, attitudes, and principles of women who had dumped babies and / or committed infanticide (Harris, 2011).

The participants provided information related to programme implementation and the information provided had a general sense that the participants were satisfied with the programme, and they all agreed that the programme was very helpful. Only those participants who took part in the workshop were chosen for the focus group discussions. Unfortunately, the participants could not discuss the possible challenges or difficulties that they might have encountered because none of them had been released after three months. That resulted in no possible recommendations for necessary improvements, for enhancement of the effectiveness of the programme. After the discussions, the participants were thanked again for their valuable contributions and fruitful deliberations; then refreshments were served.

Findings from the focus group discussions after the programme implementation

The focus group discussions were conducted by the researcher who acted as the facilitator by asking open-ended questions. These open-ended questions were centred on the topics that were presented during the programme implementation workshop. The participants were encouraged to freely air their views, opinions, and feelings during the focus group discussions that were voice recorded with their permission (Annexure C). A colleague from the northern campus was asked to take notes in order to capture the proceedings of the focus group. Those notes had to be extensive and accurately reflect the content of the discussion, as well as any salient observations of nonverbal behaviour; such as facial expressions, hand movements, and group dynamics. Participants were assured that there were no wrong answers and they were asked to respect other group members' points of view for the sake of allowing free participation. Probing was done carefully to allure some additional information from the participants and after the conclusion of the focus group discussion the voice recorder was replayed to the participants.

The participants listened to the data of the voice recording immediately while field notes were reviewed and read repeatedly, transcribed verbatim, and coded in order to identify themes (Barnett \& Casper, 2006).

- Views and perceptions of the participants about the activities conducted during the programme implementation workshop

The information that the participants previously had received during the implementation workshop was promptly reviewed and this made a whole lot of aspects in relation to baby dumping and infanticide markedly clearer, since some information was not well understood during the implementation workshop. The participants welcomed and appreciated the revision of information and were pleased that the information they received previously had been reinforced. They pointed out that the information would help them to further strengthen the application of the knowledge and skills that they had learnt during their psychosocial educational programme
- Information about enhancing knowledge and skills in relation to psychological challenges and their management The seriousness of those heinous acts of baby dumping and infanticide were once again realised by women who had dumped babies and / or committed infanticide. The participants agreed with the numerous contributory factors of baby dumping and infanticide and emphasised the reinforcement of supportive resources after different types of support were explained.

The statements below demonstrated the understanding and depth of hurting feelings of the participants:

"I am grateful to these lessons because when I think back to what has happened during that 'incidence' then I can clearly see panic, ignorance, and lack of support."

"I don't know whether we are fortunate to find ourselves under this kind of circumstance at this point in time but I wouldn't call it fortunate because what we have done was not laudable because we wouldn't have heard and learnt all these things we know now."

"These teachings are perhaps one of those experiences that I would never forget in my entire life; they changed my life, they brought back that flame of life back [sic] into me that has long been extinguished in my life through this baby I have dumped. Thank God, there is a light at the end of the tunnel."

"This training meant a lot to me. My life has changed and I am ready [to] face challenges outside."

It was clear that the participants had learnt and accumulated a lot of information from the training based on the kinds of comments they made. It was evident that the experiences the participants had during the training made them deeply realise their mistakes and they were ready to correct them when they were to be reintegrated into the society.

- Information about socioeconomic challenges of women who had dumped babies and / or committed infanticide.

The participants showed an understanding for the importance of self-respect and discipline and how essential it was to live a selfcontrolled life that shaped one's character. That information enabled them to gain a positive outlook on life and that there was always a second chance in life.

The participants appreciated the information given to them and it was evident in the statements they made about the training:

"If I had this information and knowledge before I dumped my baby, I wouldn't have done it."

"The training was really good; now I know how to deal with life challenges and no one can bring me down again. I know now how to defend myself against those who want to abuse others."

"We came to understand that there is value in every person and that each person possesses the potential to make a difference, no matter the circumstances; I have learnt that one should not look down upon oneself."

"Information about self-controlled [sic] is important; it is because we don't know ourselves that we are so vulnerable."

- Facilitating the interpersonal relationships and interpersonal skills

All good and successful interpersonal relationships are marked by effective communication that relieves any difficulty that may hamper relationships. In this study, women who had dumped babies and / or committed infanticide experienced one-sided relationships. The approaches to effective communication were designed to help the participants to communicate in a constructive manner during their period of reintegration. Strong interpersonal relationships suggested better support systems for women who had dumped babies and / or committed infanticide. That was done to place them in a better position of communicating with their family and members of the community.

Participants were informed that relationships lose their attraction when individuals did not express and reciprocate their feelings through good communication, therefore, healthy interaction was essential for healthy relationships (Management Study Guide, 2013). Women who had dumped babies and / or committed infanticide needed to acquire the qualities of good interpersonal skills that were necessary for building positive interpersonal relationships. 
The following statements by the participants are evidence of their appreciation of the training:

"I didn't even know to talk in order to defend myself but I am really glad for the lessons on how to overcome poor interpersonal relationships."

"I think the best is to [sic] never to give up on oneself no matter the circumstance or the situation you are going through because all what one needs to [sic] is to be assertive and to make your point clear."

"Losing hope is giving up on life; I am grateful that I know about the communication skills I have received through this workshop and I just need to maintain what I have received."

"I wish many women were here to learn about what we are learning now so that they may also gain this knowledge in order to be able to protect themselves against those men who just want to verbally abuse one. Because not knowing how to talk, you will just be overpowered and be left alone with pregnancies by our boyfriends."

- Information about the reintegration process challenges

The participants were informed that the main aim of the reintegration process was to assist them to be successfully reintegrated into their family and community and to avoid further criminal offending. The proposed training programme was conducted with the aim of preparing the women who had dumped babies and / or committed infanticide to cope with reintegration in order to alleviate their fears. Therefore, the researcher as the facilitator needed to boost the self-confidence of these women by altering the way they thought and / or did things. That was done through programmes and services that were provided to enhance their understanding with regard to the part they needed to play in the reintegration process.

The approaches to effective communication were designed to help them to communicate in a constructive manner during their period of reintegration. Strong interpersonal relationships suggested better support systems for women who had dumped babies and / or committed infanticide. That was done to place them in a better position of communicating with their family and members of the community.

Statements of appreciation arose from the participants:

"I am just hoping that the reintegration will be smooth and that I will be able to live happily together with my mother again because this baby dumping has really spoilt my relationship with her."

"I am praying that I will be able to put my life together again after my release; the only thing that will help me is to get a job and have a new beginning."

"I am just hoping that my family will be happy to have me around because many of my siblings were very judgmental towards what I have done"

"I am very excited about my release, and I wait to start [on] a new page."

- Information about the legal and ethical challenges

The participants were informed about the main aim of the legal and ethical frameworks. The women had to understand that even though they committed those atrocious acts that they still had the protection of the Namibian Constitution that propagated for human dignity and respect.

The educational programme was conducted with the aim of preparing these women with ethical information that enabled them to have autonomy and self-determination in decision-making. Therefore, the researcher as the facilitator needed to boost the selfconfidence of these women by altering the way they thought about themselves, knowing that there was hope.

The participants expressed their appreciation:

"I am just glad to hear that all hope is not lost with all these information [sic] I got today."

"I was in despair at first but this training came to boost me inner man [sic] with so much hope and confidence that one day all will be well again."

"I am just grateful for the workshop and it was informative and I have learnt a lot."
"I am glad for this information, and I just hope that things will work out well for me."

- Satisfaction of learning about being self and how to tackle the reintegration

The women who had dumped babies and / or committed infanticide cited their satisfaction with receiving knowledge and skills about the maintenance of self-esteem and remaining psychologically strong and rooted. They especially expressed their appreciation towards the aspect of the self-esteem that one needed to have that regard of self and not allowing any person to devalue people irrespective of who they were. They were contented with the positive feelings they had about the self and believed that they would be able to work through all those negative thoughts that had been plaguing their minds. They also stated that many areas in their lives had been transformed by this educational programme.

According to the women, the educational programme that was implemented through the workshop was an eye opener and many attested that the programme helped them to obtain knowledge and to mature into rounded adults. They believed that with the knowledge and skills they had acquired they would be able to approach the reintegration process with much confidence. They had the assurance that all would eventually work out well for them. One of the women was slightly sceptical about her release; she acknowledged that the training was a great success and that she enjoyed it but felt that she would rather remain in custody because life was cruel outside and that she enjoyed the serenity of the prison walls. She mentioned that she might perhaps change her sentiments later but as for the present, that was the state of her mind. Many women expressed they believed that the reunion with their families would be wonderful; they assumed that the information on interpersonal and communication skills they had acquired would assist them in smoothing the relationship with their families and relatives. Buttressing the above, some women mentioned:

"It is not for nothing that I received all these information [sic] on interpersonal relationships and communication skills. I will have to work on my relationship with my mother and my siblings."

"I believe all will be well as long as we are positive and accommodative towards our families."

\section{Growth and individuality}

The women were sensitised during the workshop about becoming active participants in their own lives by generating own ideas and making decisions that would influenced their lives positively. That empowerment made them aware of their independent minds and skilled in controlling and overcoming negative emotions that, in turn, influenced their thinking and behaviour. They demonstrated individual strength and maturity while displaying qualities, such as boldness and self-respect.

During the discussion, the women showed both growth and assertiveness with regard to behaviour; feelings of timidity had disappeared. Most of them developed the skill of assertiveness that was an excellent virtue of self-development and growth because they had a good understanding of who they were and believed in the value they had as human beings. That served as the basis of selfconfidence in every aspect of their lives and also assisted them to build the assurance that provided many other benefits, such as improving or mending their broken relationships with family and relatives.

During the workshop, they had been made aware of the importance of continuing to build capacity in the areas where they acquired knowledge and skills with the purpose of maintaining self-image and growth. The young women were also encouraged to carry on shaping the qualities of a moral character, since that was going to empower them and define who they were. An emotional and spiritual character was the most important principle they were expected to possess and to demonstrate inner strength that would make them different from other people. They became aware through the workshop that one needed to be sober-minded 
before engaging in any decision-making, since decisions made in times of despair had always been regarded as particularly dangerous to the human spirit. They also learnt that despair had a paralysing effect on people because it was a sickness of the spirit They realised that self-determination, courage, and faith in oneself were essential components for one to make it in life. The women found the lessons about managing despair very enlightening, since they were pivotal in enabling them to be effectively reintegrated into the society.

\section{Prospects of getting on with life}

The majority of the women who had dumped babies and / or committed infanticide were convinced that they had to get on with life though their period of being released was still some couple of years ahead. Many were still young but without education. That was worrisome to them though some received a functional literacy programme that was provided by the NCS for all illiterate offenders who came into its custody within the first 12 months of commencing serving their sentences (NCS, 2013). However, prospects of continuing educational activities based on own interest by the inmates were difficult to some extent for those of them who could not afford it. These educational programmes are initiated by the prisoners themselves in Namibia owing to limited funds in the Ministry of Safety and Security (NCS, 2013).

According to Sinalumbu (2007), the majority of the educators who provide training in the NCS are also faced with multiple obstacles; such as a lack of funds, teaching and learning materials, and workshops and in-service training, as well as classrooms that are not conducive for teaching. These obstacles hindered the optimal performance of the educators. Sinalumbu (2007) is convinced that inmate learners who are confined to correctional institutions should have access to quality education.

Though many of the women who had dumped babies and / or committed infanticide felt positive after the workshop they attended, there was some scepticism in few about the future prospects of getting on with life. Some of the participants said:

"What is life without even the basic amenities but I want to believe that things will work out for me. I trust the Lord to see me through."

"I don't know how I am going to make it out there; time will tell when we come there."

"I am sure I will meet good Samaritans who will have [sic] mercy on me; even if I have to do three domestic works on different days but I am determined to come out of this living hell."

These statements were a clear indication that some of these women who had dumped babies and / or committed infanticide had a lot to deal with depending on how resilient they were to face all the challenges that might accompany reintegration. However, their positive attitude to face their ordeal and to make a success thereof was encouraging.

\section{Conclusion and recommendation}

The programme was implemented during a three day workshop utilising the experiential approach and selecting appropriate methods for the implementation of the training programme. Programme evaluations were done at the end of the workshop sessions. Those evaluations included an evaluation at the end of the day's activities, as well as at the end of the workshop. A final evaluation was conducted three months after the implementation of the programme on the basis of a once-off focus group discussion. This focus group discussion was held with participants who attended the workshop to verify how they had internalised the information they received during the three-day workshop. None of the women who had undergone the training were released at the time of the focus group discussion; they were not yet exposed to the aftercare programme / community intervention programme. Nevertheless, during the evaluation by the women who had dumped babies and / or committed infanticide, it emerged that they were positive, and were satisfied with learning about being self and how to tackle the reintegration process. They demonstrated individual strength and maturity while displaying qualities, such as boldness and selfrespect due to the growth and the sense of individuality they had experienced. Furthermore, the prospect of getting on with life was something to look forward to for many women but some of them remained somewhat sceptical about the reintegration process.

It is recommended that the focus of future research should be:

To explore the experiences of how men need to be encouraged to help address the problem of baby dumping and infanticide;

To explore the experiences of fathers who deny taking the responsibility of fatherhood and which punitive measures should be in place to address such problems; and Additional future analyses to examine reintegration success in broader terms by using longitudinal mixed methods approaches.

Gruesome scenes of infants being dumped in rivers, dustbins, and dumpsites have become regular occurrences in Namibia, therefore, there is a need for this kind of training programme for women who have dumped babies and / or committed infanticide. This is a psychosocial educational programme that enables women to know who they are and to understand what despair is that leads to helplessness and hopelessness and how to deal with it. Therefore, it is recommended that all correctional facilities in all the regions under the auspices of the Ministry of Safety and Security should implement this training programme for women who have dumped babies and / or committed infanticide. It is also recommended that the Ministry of Safety and Security should be engaged in partnership with non-governmental organisations, ministries, and all those interested parties who desire to curb the menace of baby dumping and infanticide in Namibia. Baby dumping and infanticide have become a public health problem and it is about time that interventions are implemented to decrease this phenomenon

The government of Namibia is facing an enormous problem with baby dumping and infanticide (LAC, 2010) and this should necessitate the government to seek or identify alternative measures to save the babies by augmenting the current policies with adoption and foster home options. It is clear that there are a number of factors that are causing women to take the desperate step of dumping their babies. One contributing factor is that many people are unaware of their options when they fall pregnant and do not want the baby (LAC, 2010). Therefore, other recommendations with regard to the options should include:

'Baby boxes' known as baby hatches or angel's cradles where the babies can be safely deposited. These facilities are seen in countries like South Africa (Cape Town), South Korea, Malaysia, China, Indianapolis, and England.

Babies can be left in safe places like hospitals, police stations, fire stations, and churches under legislation that would help some mothers give up their children safely and anonymously.

More and clear information about alternatives to baby dumping; such as foster care, adoption, and institutional care. Bill boards should publish information nationwide about alternatives to baby dumping and infanticide; and Paternity tests to be made more available at a lower cost for the mother and the man who is alleged to be the father of the child. While these tests are extremely accurate, they are still far too expensive. Strong punitive actions can then be taken against the culprits who deny paternity.

\section{References}

[1] Legal Assistance Center. (2007). Guide to Maintenance Act 9 of 2003. Windhoek, Namibia.

[2] Legal Assistance Center. (2008). Gender Research and Advocacy Program. Windhoek, Namibia.

[3] Bentu, N. (2013). Why baby dumping? Retrieved December 12 , 2011, from http://www.dailynews.gov.bw/new-details.pnp?=3392.

[4] Namibia. Ministry of Gender Equality and Child Welfare. (2015). Government of the Republic of Namibia. Windhoek: Namibia.

[5] Ciccarelli, J. (2009). Baby dumping and Infanticide. Mass Media Research: Malaysia, Kuala Lumpur. 
[6] De Bruyn, M. \& Parker, S. (2005). Adolescents, unwanted pregnancy and abortion. Policies, counselling and clinical care. Chape Hill, NC, Ipas.

[7] Legal Assistance Centre. (2011). Enactment of Child Care and Protection Bill. Windhoek, Namibia.

[8] Kangandjela, L. N. \& Maupare, C. (2009). Work in progress: The Child Care and Protection Act in Namibia. University of Namibia.

[9] Greiner, M.E. (2001-2008). Baby Dump News. A Weekly EChronicle of Newborn Abandonment, infanticide, Safe Haven and related Issues. World Press. maddogmarley@worldnet.att.net.

[10] Ramklaas, N. (2010). Baby dumping on the rise in Western Cape Independent News. Cape Town, South Africa. Retrieved on, September 03, 2014, from http://www.news24.com/.

[11] Daily Maverick (2012).They opened their home and hearts to South Africa's abandoned babies. Retrieved on June 25, 2013, from http:// www.dailymaverick.co.za/.../2012-0517-they-opened-their homeand-hearts-to-south-africas-abandoned-babies.

[12] Modie-Moroka, T. (2011). Discontinuation, Detachment and Death Re-thinking Baby Dumping, Concealment of Birth and Infanticide. Retrieved September 15, 2011, from www.sundaystandard.info/article.

[13] Dzimiri, N. (2013). Concern over increase in baby dumping and infanticide. Retrieved June 06, 2014 from http://www. dailynews.gov.bw/new-details/.

[14] Salam, A. (2013). Seven main causes of baby dumping among teenagers in Kuala Lumpur. Malysia.

[15] Mazbah, T., Abdullah, N., Jaafar, N. I. M., Tagaranao, M. S. \& Safian, Y. H. M. (2014). International Journal of Technical Research and Applications. A comparative study on punishment and preventative methods of baby dumping Malaysia Perspective. E ISSN: 2320-8163, www.ijtra.com Volume-2, Special Issue 4 (July Aug 2014), PP. 24-28.

[16] Rew, L. (2005). Adolescent health. A multidisciplinary approach to theory, research and intervention. University of Texas, Austin, SAGE Publications: Thousand Oak, London, New Delhi.

[17] Watson E. (2011). System approach workbook for health education and program planning Sudburg: Jones \& Barlet

[18] Neill J. (2006). Experiential learning \& experiential education philosophy Theory, ractice \& Resources. Retrieved March 29, 2011, from

http://www.wilderdom.com/experiential/elc/ExperientialLearningC ycle.htm.

[19] Kolb, D. A. (1984). Experiential learning: Experience as the source of learning and development. Englewood Cliffs, N. J.: PrenticeHall.

[20] Hazelhurst, J. (2013). Facilitation as a teaching approach. Retrieved July 10, 2015, from https://www.vtasnetwork.files.wordpress.com/.../learning-andteaching in publicspaces-2014.pdf.

[21] Quinn, F. M. (2007). Principles and practice of nurse education. Cheltenham, U.K. Nelson Thorn.

[22] Poorman, P. B. (2002). Biography and role-playing: fostering empathy in abnormal psychology. Teaching of Psychology, 29(1), 3236. http://dx.doi.org/10.1207/S15328023TOP2901_08.

[23] Dawson, J. (2010). How to use focus groups for evaluation. eHowContributor. Retrieved February 28, 2011 from http://www.ehow.com/how-6638844 use focusgroupsevaluation.html.

[24] Pretorius, L. (2008). An educational programme to facilitate critical thinking of student nurses in Namibia. PhD. Thesis University of Namibia Windhoek Namibia.

[25] Dawson, J. (2010). How to use focus groups for evaluation. eHowContributor. Retrieved February 28, 2011 from http://www.ehow.com/how-6638844 use focusgroupsevaluation.html.

[26] Metz, A. J. R., Bowie, L. \& Blasé, K. (2007). Seven activities for enhancing the reliability of evidence based practice. Research-tothe Result Brief.

[27] Fertman, C. L. \& Allensworth, D. D. (2010). Health Promotion Programs: From theory to practice. San Francisco: John Willey \& Sons.

[28] Jacobsen, K. H. (2011). Introduction to health research methods: A practical guide.Sudbury: Jones \& Barlett.

[29] Burns, N., \& Grove, S. K. (2009). The Practice of Nursing Research: Appraisals, synthesis and generation of evidence (6th edition). St Louis, Missouri: Saunders

[30] Harris, M. J. (2011). Evaluating Public and Community Health Programs. (1st Edition). JohnWiley \& Sons. United States of America.
[31] Barnett, E \& Casper, M. (2006). Definition of Social Environment. American Journal of Public Health. Vol. 91, No.3.

[32] Management Study Guide. (2013). Retrieved November 30, 2013 , from http://www.managementstudyguide.com/communication-and interpersonalrelationship.htm.

[33] Sinalumbu, A. K. (2007). An evaluation of the roles of educators in correctional centres in Namibia. University of Namibia. Windhoek. Namibia. 